\begin{tabular}{|c|c|c|c|c|}
\hline \multirow{2}{*}{ (N) } & \multicolumn{3}{|c|}{$\begin{array}{c}\text { PORT SAID ENGINEERING RESEARCH JOURNAL } \\
\text { Faculty of Engineering - Port Said University }\end{array}$} & \\
\hline & Volume 22 & March 2018 & pp. 101:106 & 1 \\
\hline
\end{tabular}

\title{
Design and Setup for a Journal Bearing Universal Test Rig
}

\section{ABSTRACT}

\author{
Nour Marey ${ }^{1}$ El-Sayed Hegazy ${ }^{2}$ and Amman $\mathrm{Ali}^{3}$
}

A multi-function test rig was designed to facilitate experimental studies for journal bearing boundary lubrication behaviour improvement. The test rig components were designed and manufactured. It consisted of drive motor, drive shaft, bearing assembly, foundation, automatic control and data acquisition system. Fabrication and setup of the test rig were conducted taking into account industrial safety and risk assessment. Components have been individually tested and finally, overall test was performed, and was found to be quite satisfactory. The test rig unit is capable of being used for a wide range of journal bearing lubrication tests e.g., bearing material composition, lubricant additives, speed variation and bearing geometry study. Several test trials were conducted, with the aim of verifying that the mathematical outcomes derived were in complete accordance with the experimental results reached. Those endeavours have culminated in a guarantee that the practically assembled target test rig was in harmony with the inferred mathematical calculations on which the structuring process was primarily based.

Keywords: hydrodynamic lubrication, boundary lubrication, experimental test, journal bearing, propulsion shafting system

\section{INTRODUCTION}

Journal bearings are one of the important shafting elements in ship shafting propulsion systems. The design of journal bearings is considered important to avoid boundary lubrication problems. A number of design constraints had been studied through the last decade experimentally and theoretically. Here is an exposition of the endeavours exerted in the way of reaching the optimal lubricating conditions that would promote and enhance the performance of the journal bearing. Valkonen et.al [1] and [2], have become well-acquainted with the true operating conditions of hydrodynamic journal bearings, through accurately determining the oil film pressures using optical sensors.

Moreover, Ravindra et.al [3], could prove that the oil film thickness obtained experimentally was in coincide with certain values obtained theoretically. Ahmad et.al [4] and [5], has investigated the impact of changing the groove positions on the frictional force and torque. Other researches have focused their studies on the geometrical design of the two axial-groove journal bearing. Among those concerned with that issue were Binu et.al [6]. Having researched into the hydrodynamic pressure distribution in oil lubricated two-axial groove journal bearing, they have come out with the result that there was a noticeable difference between the experimentally recorded pressures and those recorded numerically.

Furthermore, Simons et.al [7] and [8], have held a comparison between different types of lubricants, including

\footnotetext{
${ }^{I}$ Arab Academy for Science, Technology and Maritime Transport, Email:

nour_marine@yahoo.com
}

\author{
${ }^{2}$ Marine Engineering and Naval Architecture Department, Faculty of \\ Engineering, Port Said University, Port Said, Egypt, E-mail: \\ Hegazy_marine@yahoo.com \\ ${ }^{3}$ Arab Academy for Science, Technology and Maritime Transport, E- \\ mail:ammanaly@yahoo.com
}

mineral based lubricants, synthetic lubricants as well as nano Cuo lubricants.

They have favored nano Cuo lubricants for lubrication purposes in journal bearing applications.

In the field of journal bearings materials, many researchers have made considerable contributions. Florian Grun et.al [9], have proved the suitability of "AlSn20Cusputter overlays" in regard to load applications, especially highly loaded ones. Those outcomes were derived after studying various types of coating materials used in different alloys. In addition, Gebretsadik et.al [10] and [11], were among those who have traced the tribological performance of thin over lays for journal bearings aiming at increasing the wear resistance and eliminating adhesive and abrasive wear. Their results obtained later have stressed that seizure load was higher for the Sn-based overlay plated materials, in fully formulated engine oil, than in base oil. Moreover, friction values were proved to be lower when the bearings were lubricated, using fully formulated engine oil, than with base oil. Finally, it was those respectable efforts that were closely traced and studied, with the aim of exploiting and building on them, when that newly introduced research was initially planned and launched. Thus, the aim of the designed structure was to create a disciplined universal test rig journal bearing catering for the requirements of experimentally studying the pressure distribution of the oil film within the journal bearing together with the factors impacting it. From the previous review, it is obvious that the presented universal journal bearing test rig would grant the possibility of studying all of those sides in a collective and a unified way. Further, that universal journal bearing test rig made it possible to closely examine the various speeds whether they were low, medium or high. These sides of study were 
not sufficiently covered or dealt with previously. That is why, the study at hand would try to fill in the gaps those previous efforts lacked.

\section{TEST RIG SETUP}

\subsection{Prime mover motor}

The selected prime mover is three phase induction motor manufactured by $\mathrm{ABB}$, which is certified as efficient and reliable for different applications. Table (1) shows the prime mover and specifications. To enable study of the effect of shaft radial speed over the oil film pressure distribution, prime mover is equipped with frequency converter which can change the velocity from $50 \mathrm{r} / \mathrm{min}$ to $1450 \mathrm{r} / \mathrm{min}$.

Table 1: Test rig prime mover specifications

\begin{tabular}{|c|c|c|c|c|c|c|c|}
\hline \multirow{2}{*}{$\begin{array}{c}\text { Output } \\
(\mathrm{Kw})\end{array}$} & $\begin{array}{c}\text { Speed } \\
(\mathrm{r} / \mathrm{min})\end{array}$ & \multicolumn{3}{|c|}{ Efficiency } & Power & Current & Voltage \\
factor & & $100 \%$ & $75 \%$ & $50 \%$ & & & \\
\hline 5.5 & 1450 & 86.5 & 87.0 & 86.1 & 0.83 & 11.5 & $380-420$ \\
\hline
\end{tabular}

\subsection{Shaft design and journal bearings}

\subsubsection{Strength checking of shaft}

Shaft calculations aim at transferring the motor power at a speed range of $50 \mathrm{r} / \mathrm{min}$ for obtaining the most possible maximum torque, considering a value of 560 M.pa for yield strength matching the mechanical properties of the

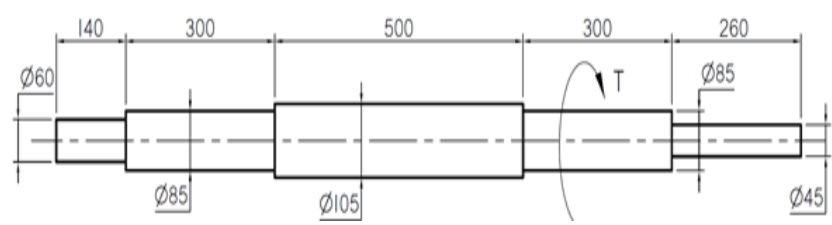

C45 round bar [15], assuming the value of "12" for the factor of safety "FOS" which is relatively high in proportion [13].That value selected regarding the factor of safety would be ascribed to the fact that the shafting system applied in most marine applications are characterized by being heavy duty shafting. The following figure is a representation of the dimensions relating to the drive shaft:

Figure 1: Drive shaft dimensions in $\mathrm{mm}$

The maximum torque working on the shaft, based on both the minimum radius, " $\varnothing 45$ ", in the shaft as well as the minimum speed limit applied $50 \mathrm{r} / \mathrm{min}$, could be derived from the following relation. [13, 14]:

where power "P" $=T \times \omega$

$\mathrm{T}_{\max }=\frac{60 \times P}{2 \pi N}=1051 \mathrm{Nm}$
$\mathrm{FOS}=\frac{\sigma_{\mathrm{u}}}{\tau_{\mathrm{all}}}$

$\tau_{\max }=\frac{\mathrm{T}_{\max } \times \mathrm{C}_{\min }}{\mathrm{J}_{\min }}$

where $\mathrm{c}_{\min }=\mathrm{d}_{\min } / 2$ and $\mathrm{J}_{\min }=\frac{\pi}{2} d_{\text {min }}^{4}$

Shear stress $\tau_{\max }=3.669 \mathrm{MPa}$

Ultimate shear stress $\tau_{u}=0.5 \times \sigma_{u}$ according to "Tresca's theory" $=23.333 \mathrm{MPa}$

$\tau_{\max }=3.669 \mathrm{MPa} \ll \tau_{u}=23.333 \mathrm{MPa}$. Hence, the maximum induced shear stress $3.669 \mathrm{MPa}$, in the shaft was much less than the ultimate shear stress $23.33 \mathrm{MPa}$, then it was quite safe.

The shaft is made of Steel C45 round bar, where this material is not to deform under high pressure, variable speed especially low speeds and should also be very hard. Steel C45 is a medium strength steel with good machinability and excellent tensile properties. The surface of the shaft was machined and polished with very high accuracy, so that there wouldn't be any damage to the sleeve and shaft. It is important to mention that a flexible coupling of the type pin and bush coupling is to be utilized for its beneficial purposes. The flexible coupling is used to let the shaft rest over the bearing material at stopping and float over the produced oil film pressure.

\subsection{Clearance calculations}

Clearance is regarded as one of the numerous serious variables that affect the journal bearing test rig performance. Other variables must be adjusted so as not to affect the clearance feature negatively. Those other variables comprise the oil viscosity, which could be drawn from the oil type and grade selection. The journal bearing test rig operating oil pressure and temperature, as well as the speed of the test rig drive shaft, the bearing grooving and other bearing design features all interrelate in the function of the journal bearing test rig lubrication system. The best method for measuring clearance is with a dial bore gage that measures the bearing inside diameter, when the test rig bearings are installed at the specified torque, without the shaft in place. Measurements should be taken at front, center and rear of each bearing position. The clearance factor, occurring between the drive shaft and the plain bearing of the journal bearing, has a starting point of "0.00075" to 0.0010 "'. The maximum as well as minimum clearance factors relating to the main journal bearing could be calculated with the help of the following formula [16]:

The shaft diameter $\times 0.00075^{\prime \prime}=$ the minimum bearing clearance

$4.132 " \times 0.00075^{\prime \prime}=0.003070866 "=(0.078 \mathrm{~mm})$.

The maximum main bearing clearance could be inferred through the following relation:

The shaft diameter $\times 0.0010^{\prime \prime}=$ the maximum bearing clearance

$4.132 " \times 0.0010 "=0.004094 "=(0.104 \mathrm{~mm})$. 
Thus, the actual main bearing clearance applied is 0.08 $\mathrm{mm}$.

\subsection{Plain bearing specification}

Figure (2) gives the main dimensions of the main bearing, where the main bearing nominal outer diameter, inner diameter, width and wall thickness were $116 \varnothing$, $105 \emptyset, 58 \mathrm{~mm}$ and $5.5 \mathrm{~mm}$ respectively. As for the secondary plain journal bearings, they were $96 \mathrm{~mm}, 85$ $\mathrm{mm}, 46 \mathrm{~mm}$ and $5.5 \mathrm{~mm}$, respectively. Also, figure (2) shows an outline of the upper and lower half sleeve

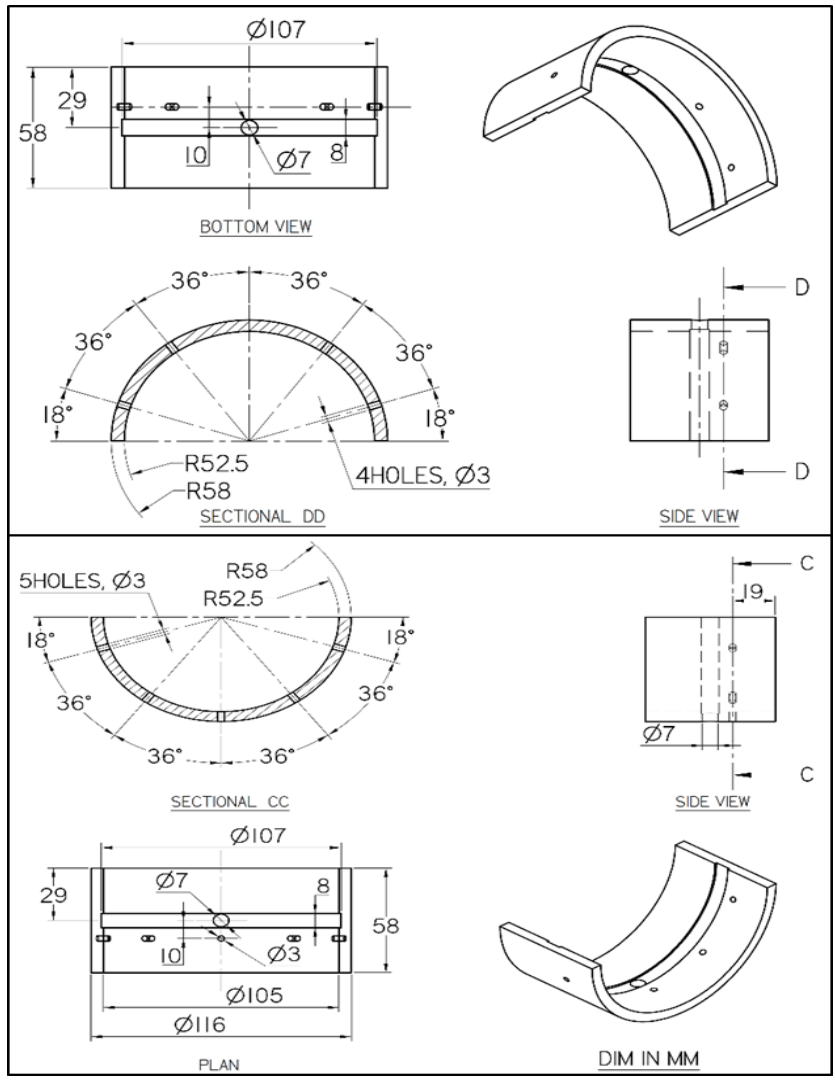

bearings, equipped with an oil groove width of $8 \mathrm{~mm}$ in the upper sleeve. The lubricating oil was supplied through the oil inlet hole in the middle of the upper sleeve, where the diameter of the oil inlet hole was $7 \mathrm{~mm}$. The upper sleeve was drilled so as to contain five holes whose diameter was

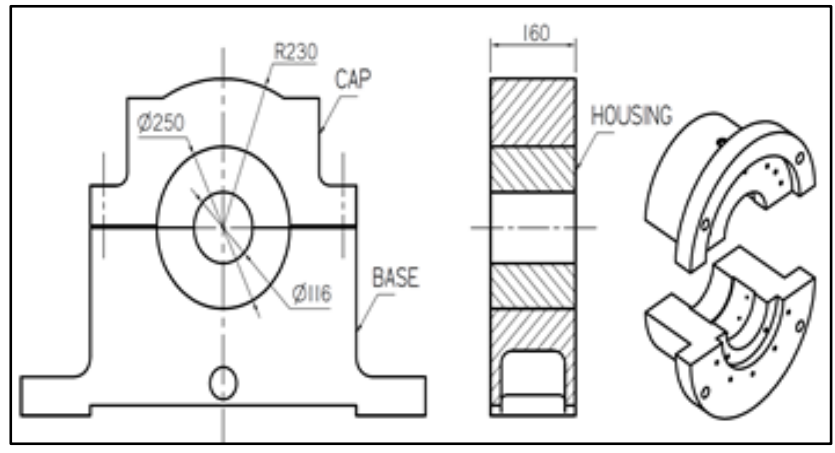

around $3 \mathrm{~mm}$ each, as is shown in the above figure. Those holes would allow the oil to flow into the opposite upper oil housing channels directly above, which, in their turn, were connected to five pressure transmitters.

Figure 2: Plain bearing dimensions in $\mathrm{mm}$

A complete design for the bearing housing was performed, and the obtained dimensions are shown on figure (3):

Figure 3: Illustrations pointing out bearing housing dimensions in $\mathrm{mm}$

\subsection{Pressure transmitters}

There were, actually, numerous reasons providing the incentive for carrying out laborious endeavors for the sake of obtaining the optimal pressure transmitters that could perform their allotted crucial tasks accurately and efficiently, shunning any likelihood of errors, miscalculations or disorder. There was a need for a type of pressure transmitters that could be characterized by a superior accuracy and an affordable cost. They also ought to have an assured guarantee from an established company that was recognized to produce certified instrumentations. That is why, the German "WIKA" company, founded in 1946, was chosen to provide the target required pressure transmitters. WIKA Company is a strong and reliable partner for all the requirements of industrial measurement technology, thanks to abroad portfolio of high-precision
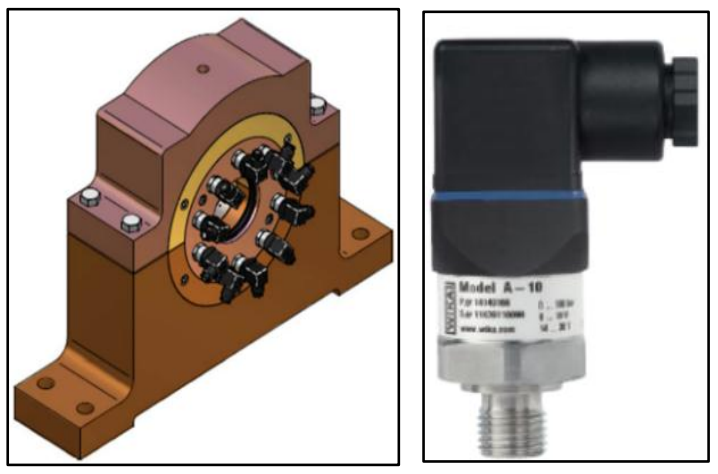

instruments and comprehensive services. Thus, the company was contacted for having the best advice in relation to the consistent pressure transmitters that could carry out the expected targets. The tips received suggested the use of pressure transmitter for general industrial applications "Model A-10", whose advantages turned to outweigh its counterparts in relation to the predetermined required goals. The following figure (4) illustrates the finally selected pressure transmitter suiting the journal bearing test rig:

Figure (4): Pressure transmitter, Model A-10 WIKA

The model "A-10" pressure transmitter, (German make) for general industrial applications, is characterized not only by its peerless compact design, but it also offers an excellent quality as well as a guaranteed source for the test report for being certified by "WIKA" maker. The target 
model "A-10" is set up for worldwide use through the international Eurasian Conformity "EAC" certification and European Conformity "CE", which indicate that the products conform to all technical regulations of "the Eurasian Customs Union" and "the European Economic Area". Besides, the A-10 pressure transmitters comprise a unit of the type "bar". In addition, the measuring range is from " 0 "and up to " 10 " bar. Further, its permissible medium temperature is " $0 \ldots+80{ }^{\circ} \mathrm{C}$ " . Moreover, its output signal ranges from " $0 \ldots \ldots 10 \mathrm{~V}, 3$ wire", with a standard accuracy of " $\leq \pm 0.5 \%$ of span". Besides, its power supply is around " $14 \ldots . . .30 \mathrm{~V} \mathrm{DC}$ ".

\subsection{The electrical control panel}

It wouldn't have been possible for the universal test rig to accurately perform the crucial tasks allotted to it, if it hadn't been for a well-organized control panel. The control panel would carry out the mission of manipulating, monitoring and operating the whole of the structure. Further, it would have the ability of transmitting the analogue data received from the ten pressure transmitters into digital data via the "Schneider Electric Zelio Logic Control with Display".

The electrical control panel contains the following items, which ensure the efficient operation of the test rig:

- A main isolating switch, which connects the three-phase power supply to the control panel.

- Three fuses to protect the whole panel.

- Three current transformers.

- A miniature circuit breakers "Mcb" three poles, 16 A from Siemens.

- Four miniature circuit breakers, one pole from Siemens.

- A power supply from "OMRON" $2.5 \mathrm{~A}$, which converts the power supply from 220 AC into 24 DC.

- Three Siemens contactors for the three motors, namely, the drive motor, the lubrication pump motor in addition to the cooling pump motor.

- The 1.5 A Schneider overload assigned with the

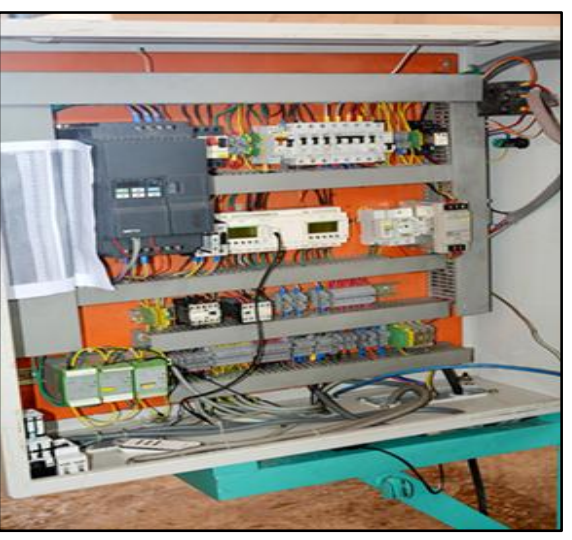

protecting the lubrication pump motor.

- A 16 A Schneider relay fitted to manipulate the preheating oil coil.

- "Two Schneider Electric Zelio Logic Controls with Display".

- A power inverter of the make "Nietz", to control the motor speed.

- A digital multimeter

- A potentiometer

- Indication lamps for the ten pressure transmitters.

- A digital temperature controller.

The following figure illustrates the electrical control panel relating to the journal bearing test rig after assembly:

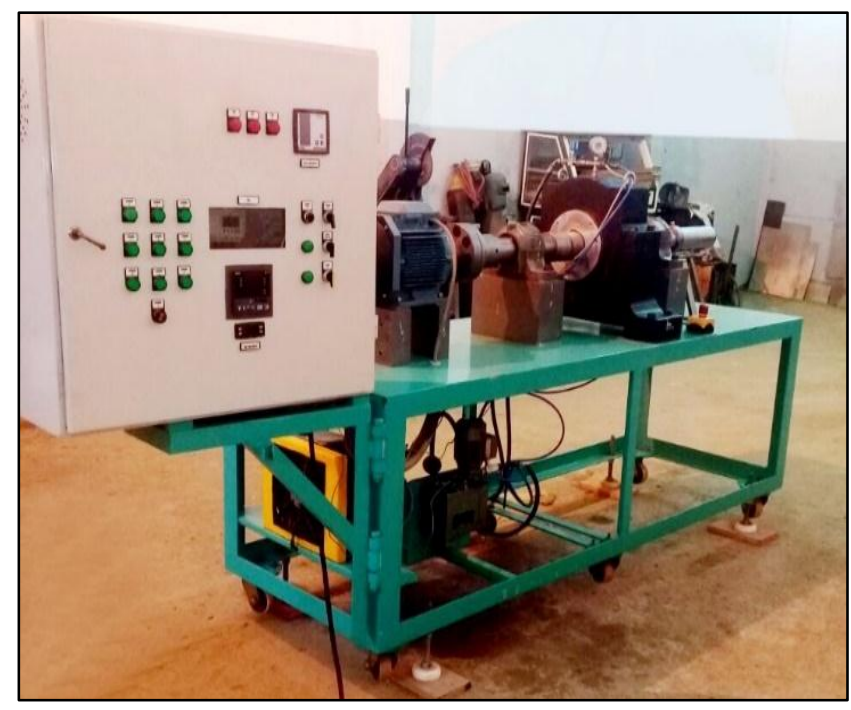

Figure (5): Control panel and data acquisition

\subsection{Journal bearing test rig assembly}




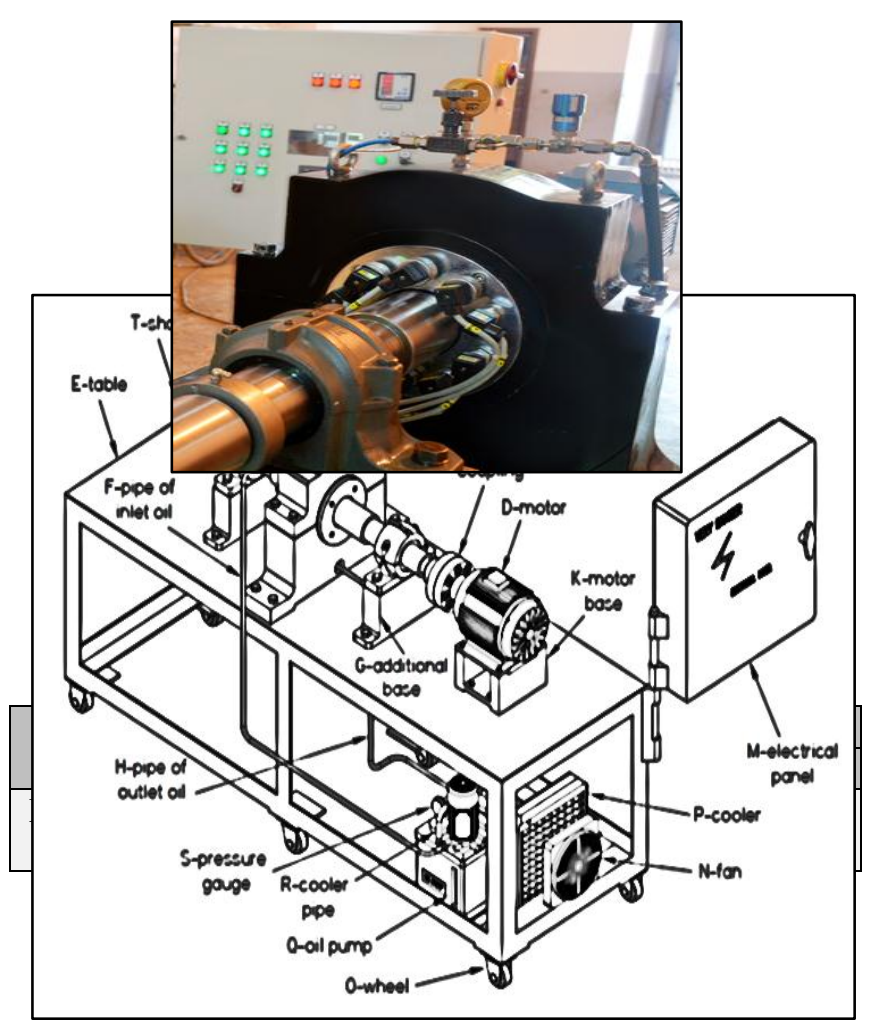

Assembly process entailed many trials for the sake of obtaining system integrity and shafting alignment according to risk assessment criteria. Figure (6) shows a

\begin{tabular}{|c|c|c|c|c|}
\hline \multirow{2}{*}{$R P M$} & Experimental & Theoretical & Deviations & Error \% \\
\cline { 2 - 5 } & $\mathrm{P}_{0} / \mathrm{P}_{\max }$ & $\mathrm{P}_{0} / \mathrm{P}_{\max }$ & $\mathrm{P}_{0} / \mathrm{P}_{\max }$ & $\mathrm{P}_{0} / \mathrm{P}_{\max }$ \\
\hline 50 & 0.4844 & 0.47 & -0.0144 & $3.06 \%$ \\
\hline 100 & 0.4862 & 0.51 & +0.0238 & $4.66 \%$ \\
\hline 150 & 0.4865 & 0.52 & +0.0335 & $6.44 \%$ \\
\hline 200 & 0.4923 & 0.53 & +0.0377 & $7.11 \%$ \\
\hline
\end{tabular}

sketch for the test rig with its different components, after assembly, as well as a photo for the test rig in place.

Figure 6: Over all test rig

\section{VALIDATION OF TEST RIG RESULTS}

On carrying out an experimental study on the plain journal bearing using the test rig under consideration, it is important to check the consistency and validation of its derived results. The oil pressure distribution, at different rotating speeds, around the plain bearing, is measured by the aid of ten pressure transmitters, installed all around the circumference of the bearing, as shown on figure (7):
Figure 7: An illustration of the angles and distribution relating to the ten pressure transmitters.

\subsection{Theoretical results}

To check the validity of the test rig results, the following procedures were followed:

Calculation of the nominal bearing pressure: $\mathrm{p}=\frac{W}{2 r L}$

Where $\mathrm{W}=727.9 \mathrm{~N}, \mathrm{r}=52.5 \mathrm{~mm}$ and $\mathrm{L}=58.0 \mathrm{~mm}$

So, $\mathrm{p}=1.19$ bar

Calculation of the bearing characteristic No (Summerfield number) " $\mathrm{S}$ " is as follows:

"S" $=\left(\frac{r}{c}\right)^{2}\left(\frac{\mu \mathrm{N}}{\mathrm{p}}\right)$

Where the oil viscosity " $\mu$ " $=0.0967$ Pas, radial clearance "C" $=0.04 \mathrm{~mm}, \mathrm{r} / \mathrm{m}$ "N" = 50;100; 150 and 200 and last but not least the l\d ratio was found out to be 0.55

Using the charts of "Raimondi and Boyd" [13], we can find the value of the maximum film pressure ratio " $\mathrm{P}_{0} / \mathrm{P}_{\max }$ ", as is shown in the following table:

Table (2): Theoretical values obtained under various speed

\subsection{Experimental results}

Table (3) gives a comparison between the technical data obtained theoretically, as explained above, and the same data as obtained from experimental study.

Table (3): Test rig validity ascertained through experimental and theoretical values, which are proportionally on the rise, in relation to both the experimental ratio $\mathrm{P}_{0} / \mathrm{P}_{\max }$, and that derived theoretically.

From the data given in table (3), it is clear that there is a good agreement between experimental and theoretical results. Furthermore, the resulting deviation and error outcomes clearly appear to be so slight and marginal in their values. It is noteworthy that all the previously derived and recorded values reflect a notable consistency and much accordance with their counterparts in the research introduced by Binu et. al [6]. However, it is clear that the recoded values relating to the error percentage in the research at hand appear to be notably lower than their peers in the above mentioned research of Binu.

Such results undoubtedly manifest the validity of the test rig for successfully carrying out the tasks for which it was primarily planned.

\section{Conclusion}

To sum up, essential required calculations have been carried out for the buildup of the universal journal bearing test rig. It has been planned, designed, manufactured and assembled according to a number of considerations among of which comprise the design material stresses, 
manufacturing standards as well as the assembly risk assessment criteria. Furthermore, all of the consistent and available components and equipment have been selected and used with great care and precision for the sake of meeting the planned target. Finally, the design and development of the universal test rig to stimulate the practical conditions of standard journal bearing for a ship power transmission is considered. The test rig has been tested for different speeds and the results were found to be harmonious with theoretical investigations. Currently, tests are being performed to study the effect of design parameters, e.g. speeds and oil specifications, on the oil film lubrication performance, and will be published as soon as finished.

\section{Nomenclature}

\section{REFERENCES}

[1] Antti Valkonen, "Doctoral Dissertation, oil film pressure in hydrodynamic journal bearings", Department of Engineering Design and Production, Helsinki University of Technology, Finland, ISBN 978-952-248-162-7, 2009.

[2] Valkonen, A.; Juhanko J. \& Kuosmanen P., "Measurement of oil film pressure in hydrodynamic journal bearings", 7th International DAAAM Baltic Conference \&Industrial engineering, Tallinn, Estoni, 22-24 April 2010.

[3] Ravindra R. Navthar, N.V. Halegowda, "Experimental Investigation of Oil Film Thickness for Hydrodynamic Journal Bearings", ISSN: 1662-7482, Vols. 110-116, pp 2377-2382, 2011.

[4] Mohamad Ali Ahmad, Salmiah Kasolang, Rob DwyerJoyce, "The Effects of Oil Supply Pressure at Different Groove Position on Frictional Force and Torque in Journal Bearing Lubrication", www.sciencedirect.com, Procedia Engineering 68 (70-76), 2013.

[5] Mohamad Ali Ahmad, Salmiah Kasolang, Rob DwyerJoyce, "Experimental study on the effects of oil groove location on temperature and pressure profiles in journal bearing lubrication", www.elsevier.com/locate/triboint, Tribology International 74 (79-86), 2014.

[6] K.G. Binu, K. Yathish, R. Mallya, B.S. Shenoy, D.S. Rao, R. Pai, "Experimental study of hydrodynamic pressure distribution in oil lubricated two-axial groove journal bearing", 4th International Conference on Materials Processing and Characterization, www.sciencedirect.com, Materials Today: Proceedings 2 (3453 - 3462), 2015.

[7] G.F. Simmons and S.B. Glavatskih, "Synthetic lubricants in hydrodynamic journal bearings: experimental results", Lulea University of Technology, Division of Machine Elements, Lulea, Sweden Tribology Letters, 42, pp. 109-115, 2011.
[8] Gregory F. Simmons, Doctoral THESIS, "Journal Bearing Design, Lubrication and Operation for Enhanced Performance", Lulea University of Technology, Department of Engineering Science and Mathematics, Division of Machine Elements, 2013.

[9] Florian Grun, Istvan Godor, Walter Gartner, Wilfried Eichlseder, Tribological performance of thin overlays for journal bearings, www.elsevier.com/locate/triboint, Tribology International 44 (1271-1280), 2011.

[10] Daniel W.Gebretsadik, Jens Hardell, Braham Prakash, "Tribological performance of tin-based overlay plated engine bearing materials", www.elsevier.com /locate/triboint, Tribology International 92 (281-289), 2015.

[11] Daniel W.Gebretsadi, Jens Hardell, Braham Prakash, "Friction and wear characteristics of different $\mathrm{Pb}$-free

$\begin{array}{cl}\mathrm{C} & \text { Radial clearance, mm } \\ \mathrm{c} & \text { Radius, mm } \\ \text { FOS } & \text { Factor of safety } \\ J & \text { Polar moment of inertia } \\ \mathrm{L} & \text { Bearing length, mm } \\ \mathrm{N} & \text { Rotational speed of journal, rpm } \\ \mathrm{P} & \text { Motor power, Kw } \\ \mathrm{p} & \text { Nominal bearing pressure, Bar } \\ \mathrm{r} & \text { The radius of drive shaft, mm } \\ \mathrm{S} & \text { Summerfield number } \\ \mathrm{T}_{\max } & \text { Max torque, Nm } \\ \mathrm{W} & \text { Shaft weight, N } \\ \sigma_{u} & \text { Yield strength, MPa } \\ \tau_{\max } & \text { Max shear stress, MPa }\end{array}$

bearing materials in mixed and boundary lubrication regimes", www.elsevier.com/locate/wear, wear 340-341 (63-72), 2015.

[12] Daniel W.Gebretsadik, Jens Hardell, Braham Prakash, "Seizure behaviour of some selected $\mathrm{Pb}$-free engine bearing materials under lubricated condition", www.elsevier.com/locate/triboint, Tribology International 111 (265-275), 2017.

[13] Richard G. Budynas and J. Keith Nisbett, "Shigley's mechanical engineering design, tenth edition", McGrawHill Education, 2 Penn Plaza, New York, NY 10121: McGraw-Hill Education, 2015.

[14] Ferdinand P. Beer, "Mechanics of materials, Seventh edition", McGraw-Hill Education, 2 Penn Plaza, New York, NY 10121: McGraw-Hill Education, 2015.

[15] "Steel material C45", Available from: http://www.steelgr.com/Steel-Grades/Carbon-

Steel/c45.html.

[16] "Bearing clearance", Available from: www.files.engineering.com/download.asp?folder.

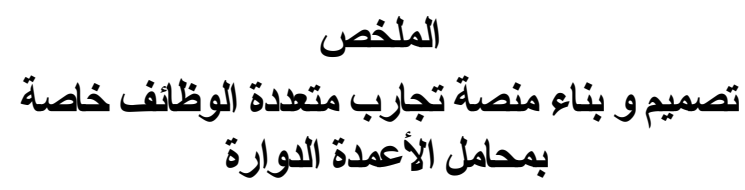


• م القيام بتصميم و بناء منصة تجارب متعدة الوظائف من أجل الجل

الوفاء بأغراض الاراسة المتعلقة بطبقة زيت التزييت داخل محامل الأعمدة الدوارة.

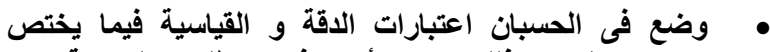

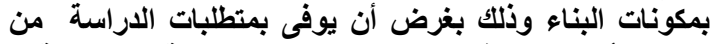

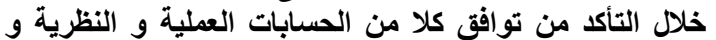

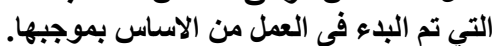

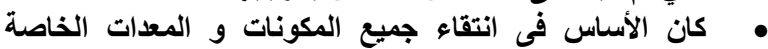

بالبناء هى الاقة الفائقة بقدر ما أمكن وذلتك من أجل استيفاء

شروط الحصول على نظام محكم متناغم يوفى بأغراض البحث

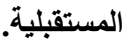

• تم مراعاة أن تكون كل أجزاء بناء منصة التجارب متصفة

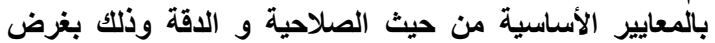

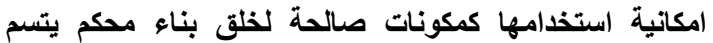

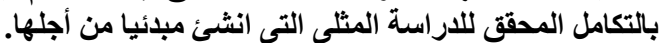

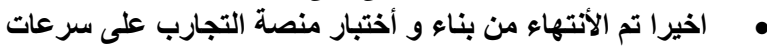

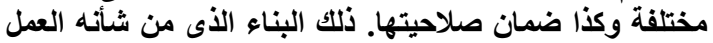

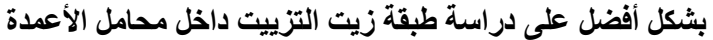

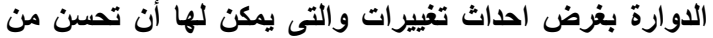

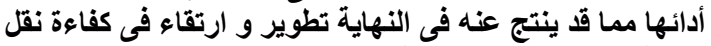

الطاقة فى التطبيقات البحرية. 